
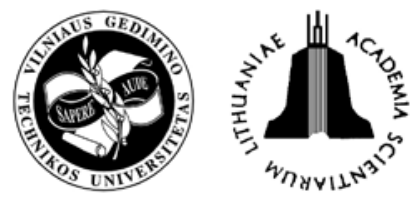

TRANSPORT

2008

23(2): 161-166

\title{
TELECOMMUNICATIONS AND INTRA-URBAN TRIP PATTERN IN ZARIA
}

\author{
Andrew Ubogu \\ Dept of Geography, Ahmadu Bello University, Zaria, Nigeria. E-mail: ubogu2001@yahoo.com.
}

Received 11 October 2007; accepted 1 February 2008

\begin{abstract}
The concern over the likely impact of space-adjusting technologies like telecommunications has attracted considerable attention in most studies. The focus of this paper is to examine how the proliferation of telecommunications affects intra-urban flow of people in a medium size urban centre. This is with a view to understanding the implications of the use of Information and Communication Technology (ICT) on travel pattern in a sub-Saharan urban centre like Zaria, Nigeria. In doing this however, attempts were made to answer the following questions: How have telecommunications substituted trip patterns in the study area? Does telecommunication usage eliminate all types of trips and to what extent has it helped to eliminate urban trips? In trying to provide answers to these questions, this study obtained purposive data from 335 telecommunication users that were carefully sampled. The results thereafter established that $76.7 \%$ of the respondents substitute certain trips in the city and that telecommunications do not eliminate the physical movements of the residents surveyed. Furthermore, results also depict that not all trip types in the city are significantly substituted by telecommunications, rather the usage of ICT has tremendously helped to complement intra-urban trip types in the city. The implications of these findings therefore are that with the improvement and subsequent increases in high tele-density in the area, least-cost travel planning will be ultimately achieved.
\end{abstract}

Keywords: telecommunications, transport, trip technologies.

\section{Introduction}

The concern of transportation planners is to adopt strategies that will reduce the economic, social, and environmental cost of travel. The challenge for cities is to manage urban travel demand without degrading the quality of life (De Souza 2005). As a result of the improvement in telecommunications, Nigeria has joined the famous countries in Africa with high tele-density (telephone lines per 1000 people) with a standard of $1 \%$ that translate to one telephone line per 100 people (V-mobile News 2004). Telecommunications and transportation share similar trait as both help to overcome space. With the era of Information and Communication Technology (ICT), travel pattern and dependence on physical movements in urban centres are highly influenced by telecommunication systems. As rightly noted by Niles (1994) telecommunications produce an overall net reduction in all household driving, a net energy benefit of generally positive performance, a reduction in vehicle miles travelled per annum, and satisfaction result to urban inhabitants.

As it is with transportation, telecommunication technology facilitates the transmission of large quantities of information rapidly at a cost that make transportation only slowly increase with distance (Gbadamosi 2004). These information and communication technologies re- fer to all those means and methods of transmitting information, ideas, images and non-tangible messages from one place to another (Ogunsanya 2005).

Telephenomena encompassing all telecommunication-related measures aimed at transmitting messages and information include telecommuting, telework, teleconferencing, teleservices, etc. The major channels through which these activities can be facilitated could be through the use of telephone, Internet, radio message and fax.

Indeed, in the geographic study of movement of spatial phenomena such as people, goods, information, ideas and news, distance is an important factor. The friction of distance is an implicit determinant of material flows and human spatial behaviour. Be that as it may, the advent of telecommunication devices is aiming to substitute, complement and enhance trip patterns, so the urban movement pattern is bound to be modified. Moreover, with the altering and outright elimination of the constraint of distance, places are becoming more accessible thus reducing intra-urban economic and social inequalities. Consequently, the need to travel within the city and the landuse structure is inadvertently altered.

In Nigeria presently, and Zaria in particular, the proliferation of telecommunication systems such as fax, Internet and more importantly mobile phones has im- 
posed a spatial behaviour consistent with ICT age. For this reason therefore, it is imperative to assess its impact on travel behaviour. This study fundamentally seeks to examine the impact of telecommunication usage on intra-urban trip pattern and to determine as to what extent the proliferation of mobile phones has eliminated urban trips within Zaria.

\section{Theoretical framework}

Intra-urban telecommunication volume is made up of electronic and optical information flows while surface travel volume concerns vehicular trips. Both methods enhance spatial interaction. Movement between places by people, goods or information does not occur in isolation but is stimulated by particular forces (Lloyd and Dicken 1972). Interaction in itself as suggested by Ullman (1956) is determined by three fundamental factors of complementarity, transferability and intervening opportunity. Complementarity and transferability are necessary conditions for movements to be initiated between one point and another, while intervening opportunity is often a modifying influence upon the orientation and volume of resulting flows. Therefore, to explain why things move in space, we need the ideas of complementarity, the relative attractiveness of alternative destinations, the technology needed to overcome the friction of distance and intervening obstacles to interaction (Abler et al. 1972).

More often than not, the disparity in urban land use structure is an underlying factor responsible for flows between and amongst different parts of a city. Ogunbodede (2002) noted that interaction and movement in space might be seen as a means of closing the spatial gap in urban centres. Journey to work, to recreational centres, to market, to commercial centres, to schools and the like constitute aspects of this urban movement and interactions.

Again, evidence from the literature has suggested that the spatial behaviour of urban residents in their frequency of trips for shopping and mobility is dictated by the concept of range and threshold. The basic thrust of the range stipulates that there is a maximum distance that consumers are willing to travel to patronize goods and services offered by a particular function or landuse. Consequently, each resident willing to patronize a service has to overcome the friction of distance that involves a time cost. The threshold on the other hand relates to the minimum population required to sustain a service (Ayeni 1975).

Variations in urban landuses initiate movements. Movement of every sort creates spatial structures and once established, such spatial arrangements influence subsequent movements (Abler et al. 1972). The land use pattern of Zaria, be they industrial, commercial, educational, residential, recreational, administrative, agricultural, all give rise to massive flows of people, goods and information mostly during the rush hours. The journey to work is the single most regular pattern of trips in cities. Imperatively, the option of altering or eliminating the temporal and spatial pattern of certain trips using telecommunications is of utmost interest to transportation planners. In view of this however, the use of telecommunication technology has a direct impact on the transport system.

The relation between telecommunications and transportation is somewhat shrouded in considerable degree of ambiguity in spatial studies, as one is seen to eliminate the other and at the same time complement each other. The literature is replete with studies detailing the impact of telephones on trip behaviour (Moktanan 1991; Hanson 2000; Ogunbodede 2002; Gbadamosi 2004). Specifically, this impact exists in the form of a symbiotic interactive relationship between transportation and telecommunications. The first of this relationship is that one has the capacity to substitute the other. By and large, the availability of telecommunications inadvertently reduces the need to travel (U. S. DOE 1993), complementarity is the second interactive relationship. Instructively, telecommunications and transport both complement each other as an increase in one mode generates additional travel between two modes through proper routing and tracking of movements. The third relationship is enhancement. This effectively contributes to the efficiency of the other system.

More importantly, the development of telecommunications, particularly the telephone, enables the potential trip maker to lay the foundation for more productive travel through remote negotiation, fact finding or troubleshooting that sometimes makes a trip unnecessary (Niles 1994). Nevertheless, opinions still differ as to whether telecommunications actually generate more trips or curtail them. Indeed, as observed by Hoyle and Smith (1998) telecommunications have the potential to abolish distance in sparsely populated areas. The telephone is able to substitute journeys for socials, information and financial purposes but its usage is dominated by the better-off mobile phones. One the other hand, experience has shown that it does not totally substitute human movement involving transportation modes but it enhances movement (Gbadamosi 2004).

\section{Database and methods}

\subsection{Study area}

Zaria is located at latitude $11^{\circ} 3 \mathrm{~N}$ and longitude $7^{\circ} 42 \mathrm{E}$. It is about $643.7 \mathrm{~km}$ off the coast of Nigeria. It lies on the high Hausa plains of Northern Nigeria, in the sub-Saharan Africa. The city is the second largest next to Kaduna, in Kaduna State. Zaria has become a nodal point by virtue of its location in the northern Nigeria and in terms of its rail and road transport system. The population of the town has been growing rapidly in recent time. The rapid and persistent increase has been attributed to natural increase due to improved medical facilities and sanitation practices as well as migration from other areas. Majority of the inhabitants are Hausa Fulani with a mix of other ethnic groups such as Ibos, Yorubas, Efiks, Ibibios, etc.

It is one of the major indigenous cities founded as early as $1536 \mathrm{AD}$ as the capital of Zazzau Kingdom. The town being indigenous suggests that it has evolved through a period of both pre and postcolonial urbanization. Urban 
Zaria has four clusters - Zaria city, Tudun-Wada, Sabon Gari, and Samaru. The space economy of the town is comprised of industrial, commercial, educational, residential, agricultural and transportation land uses.

\subsection{Analytical methods}

The data for this paper was obtained through the administration of a questionnaire specifically designed to gather information on, among other things, the impact of telecommunication usage on intra-urban trip pattern. The questionnaires were administered in two clusters out of the four in the town, namely Sabon Gari and Samaru between September-October 2005. The choice of these sampling points was designed to reflect the general land use character of the entire town such as industrial, commercial, educational, residential, agricultural and transportation land uses. In each of the area sampled, six pay phone centres and Internet cafes were purposefully chosen. Two basic reasons informed the choice of these centres.

First, every user of these centres aims at overcoming space through telephenomenal interaction. Secondly, it is an ideal place to interview users for their preference of telecommunications as a mode of interaction. Consequently, willing respondents were randomly administered with a questionnaire. The questionnaire was thereafter coded and analysed. In all, 335 questionnaires were administered. A Chi-square test was primarily used to assess the significance of the opinions of respondents as to how their use of telecommunications has reduced their physical movements. More so, simple descriptive analysis of percentage frequency has been employed in order to display the extent at which telecommunications affect urban trip types.

\section{Results and discussion}

The understanding of urban systems and their morphology lies in the periodic movement of people and their various forms of intra-urban trip making to and from different land uses for work, social activities, shopping, business and other recreational purposes. Zaria as an urban centre with distinct urban land uses is no exception to this routine movement pattern. Although, these various trip types still persist, telecommunication usage in the town has somehow modified and complemented these daily trip types. The use of telecommunications has contributed to the socio-economic development of Zaria. Their effect can be felt in the areas of business transactions, educational, leisure, remote work and other social activities.

\subsection{Socio-economic characteristics of respondents}

The distribution of the sampled respondents by their socio-economic characteristics shows that nearly $59 \%$ of the respondents are males by sex while $41 \%$ were females; this is a reflection of the sexual composition of most urban centres in Nigeria. The dominance of male population is perhaps because of more adventurous and migratory nature of males than females. Again, the age characteristic of the respondents reveals that about $7 \%$ of those that make use of various telecommunication devices are less than 20 years of age. The age brackets of 21-29, 30-39; 40-49 and 50 and above accounted for $58.2 \%, 25.6 \%, 8.1 \%$ and $1.1 \%$ respectively. In all, about $91.9 \%$ of the sampled population fall within the productive age group of 21-40. With respect to the occupational status of the respondents, about $25 \%$ are students while $26.9 \%$ are public servants with $36.2 \%$ accounted for by traders and those in private business, thus implying that business transactions could be affected by telecommunications. Furthermore, those that are unemployed and other unidentified occupations represented $11.9 \%$. The literacy rate is high as those without formal education accounted for by mere $3.9 \%$ of the sample population.

\subsection{Telecommunication usage and transport system}

The distributional pattern of those who make use of various telecommunication devices for their daily activities shows that about $93.7 \%$ of the respondents make use of one telecommunication device or the other while $6.3 \%$ do not have any devices but patronize pay phone or call centres for their routine troubleshooting, enquiries and interaction in carrying out their daily activities in the city.

The analysis of the type of telecommunication devices used, revealed that majority of the respondents of about $61.9 \%$ have GSM only; $3.3 \%$ have the landline; $12.5 \%$ have both landline and GSM; $10 \%$ have GSM, landline and Email; $1.7 \%$ have other types of devices while the remaining $10.6 \%$ represent those without telecommunication devices but who patronise different call centres. The portability, efficiency and mobility of the GSM over other modes is largely responsible for the preponderance of this system in their intra-urban interaction.

As shown in Table 1, the distribution of the frequency of telecommunication usage in carrying out daily activities shows that $44.2 \%$ make use of these devices

Table 1. Distribution of the frequency of respondents' use of telecommunications in carrying out their daily activities

\begin{tabular}{|c|c|c|c|c|c|c|}
\hline \multirow{2}{*}{ Frequency of Use } & \multicolumn{2}{|c|}{ Sabon Gari } & \multicolumn{2}{|c|}{ Samaru } & \multicolumn{2}{|c|}{ Total } \\
\hline & $N$ & $\%$ & $N$ & $\%$ & $N$ & $\%$ \\
\hline Many times a day & 68 & 41.7 & 80 & 46.5 & 148 & 44.2 \\
\hline Once every day & 61 & 37.4 & 60 & 34.9 & 121 & 36.1 \\
\hline Once in two days & 21 & 12.9 & 20 & 11.6 & 41 & 12.2 \\
\hline Once a week & 08 & 4.9 & 08 & 4.7 & 16 & 4.8 \\
\hline Occasionally & 05 & 3.1 & 04 & 2.3 & 09 & 2.7 \\
\hline Total & 163 & 100 & 172 & 100 & 335 & 100 \\
\hline
\end{tabular}


many times a day for their business and social interactions as well as making enquiries before certain trips are embarked upon. Again, 36.1 \% make use of telecommunication system at least once every day. The frequency of telecommunication usage by other respondents reveals that $12.2 \%, 4.8 \%$; and $2.7 \%$ respectively accounted for once in two days, once a week and occasionally. This glaring picture should be expected as the use of these devices are far cheaper, safer and with little or no inconveniences in their adoption and usage.

The urban transportation system of the study area is far more unreliable as it is prone to certain traffic bottlenecks. These bottlenecks arise from intermittent stops and traffic delays occasioned by carrying and alighting of passengers as in public transport system. Also, delays may result from traffic congestions. In general, various modes of transportation systems are used as reported by the respondents. They are Bus system, Public motorcycle, Private car, bicycle and walking. All these accounted for $46.9 \% ; 31.9 \%, 3.0 \% ; 1.8 \%$ and $16.4 \%$ respectively. This result indicates that majority of the respondents that require and use transportation system for their daily activities is about $83.6 \%$ of the population who commute within the city on a daily basis using one transport system or the other. More importantly, the impact of telecommunication use on these routine trip patterns within the city is likely to alter and modify the intra-urban movement pattern (Gbadamosi 2004).

\subsection{Telecommunications and trip substitution}

Indeed, as a matter of resultant outcome rather than initial intent, telecommunications frequently substitute for transportation. People working in public service, business and other sectors often take actions to use telecommunications that yield substitutions for transportation (Niles 1994). The resultant mobility pattern includes many ways in which telecommunications permit new methods of doing things that would have formerly required a trip. Both telecommunications and transport fulfil requirements for social and economic interactions, transactions and other relationships although in different ways. The use of telecommunications offers a very good option of eliminating or minimizing physical movement particularly as a result of cost and time of travel. The substitution of telecommunications for physical movement is of great interest to most planners as it offers remedy for social costs.

As indicated in Table 2, majority of the respondents wittingly or unwittingly substitute their intra-urban trips with telecommunications. Of the entire population sampled, $76.7 \%$ substitute some of the daily trips with telecommunications system while $23.3 \%$ reported that they do not alter their trip patterns. The substituted trips occur every day ( $8.0 \%)$; every other day (19.1\%) and occasionally (49.6\%). This confirms what is already known that telecommunication usage could be used to replace off-peak trips, rather than morning trips (Ogunbodede 2002)

It is imperative to note that every telephone conversation, every data transmission and every e-mail message or fax represents a potential substitution of telecommunications for physical movement of people. However, there are variations as to the time and type of trip that telecommunications can act as a substitute for transportation: $76.7 \%$ that substitute their trips; $3.5 \%$ reported substituting some trips in the morning and $32.3 \%$ in the afternoon. Moreover, other respondents substituted their evening and night trips, $34.2 \%$ and $22.6 \%$ respectively. Incidentally, $7.4 \%$ reported that they substitute some necessary trips with telecommunications at any time (Table 3). In this manner, physical movement of people in Zaria is reduced to some extent. This confirms what is already known that telecommunication usage could be used to replace off-peak trips rather than morning trips (Ogunbodede 2002). However, amongst those respond-

Table 2. Respondents' frequency of substituting their periodic movements with telecommunication system

\begin{tabular}{|c|c|c|c|c|c|c|}
\hline \multirow{2}{*}{ Frequency of Substitution } & \multicolumn{2}{|c|}{ Sabon Gari } & \multicolumn{2}{|c|}{ Samaru } & \multicolumn{2}{|c|}{ Total } \\
\hline & $N$ & $\%$ & $N$ & $\%$ & $N$ & $\%$ \\
\hline Every day & 18 & 11.0 & 09 & 5.2 & 27 & 8.0 \\
\hline Every other day & 21 & 12.9 & 43 & 25.0 & 64 & 19.1 \\
\hline Occasionally & 78 & 47.9 & 88 & 51.2 & 166 & 49.6 \\
\hline Not at all & 46 & 28.2 & 32 & 18.6 & 78 & 23.3 \\
\hline Total & 163 & 100 & 172 & 100 & 335 & 100 \\
\hline
\end{tabular}

Table 3. The time of the day telecommunications act as substitute for respondents' movement

\begin{tabular}{ccccccc}
\hline \multirow{2}{*}{ Frequency of Substitution } & \multicolumn{2}{c}{ Sabon Gari } & \multicolumn{2}{c}{ Samaru } & \multicolumn{2}{c}{ Total } \\
\cline { 2 - 7 } & $N$ & $\%$ & $N$ & $\%$ & & $\%$ \\
\hline Morning & 05 & 4.3 & 04 & 2.9 & 9 & 3.5 \\
\hline Afternoon & 34 & 29.1 & 49 & 35.0 & 83 & 32.3 \\
\hline Evening & 41 & 35.0 & 47 & 33.6 & 88 & 34.2 \\
\hline Night & 28 & 23.9 & 30 & 21.4 & 58 & 22.6 \\
\hline Anytime & 09 & 7.7 & 10 & 7.1 & 19 & 7.4 \\
\hline Total & 117 & 100 & 140 & 100 & 257 & 100 \\
\hline
\end{tabular}


ents that reported substitution of their trips, trips for social activities and business accounted for a large proportion of the sampled population. This is evident from the $56.0 \%$ and $37.3 \%$ that reported substituting their social and business trips. Incidentally such trips are relatively substitutable. Trips meant for enquiries, social visits, greetings, business transactions, etc. are often substituted with telephone calls and e-mails because it is faster and has the quick response time. Trip to work, recreation and shopping accounted for a marginal percentage of $1.2 \%$; $4.3 \%$ and $1.2 \%$ respectively (Table 4 ). This result is consistent with the opinion of Hoyle and Smith (1998), and Tolley and Turton (1995) that telephone is able to replace journeys for social, information and financial purposes.

Strictly speaking, the use of telecommunications has a stimulative effect on travel by making the transportation system efficient. People use various telecommunication devices to make transportation and travel safer, faster, more reliable and more productive. Indeed, the use of cellular phones makes people stay accessible and productive. As Table 5 depicts, overwhelming majority of the respondents agreed that the two systems both complement each other. Nevertheless, there seems to be a variation in the trip type complemented by telecommunication system. It is noteworthy to stress that $40.9 \%$ of the entire respondents identified social trips as being highly complemented by telecommunication system. This is closely followed by business trips $(25.1 \%)$; trip to work $(21.5 \%)$ shopping trips $(11.0 \%)$ and recreational trips $(1.5 \%)$.

This trend gives credence to our earlier observation that social and business trips are easily susceptible to modifications, alterations and reduction by telecommunication usage. More often, telecommunications enable a wide variety of new last-minute information flows that sometimes generate a personal travel through attractive invitations and compulsory orders to attend to.

Again, the exact impact of telecommunications on trip pattern in the city was subjected to Chi-Square test as shown in Table 6 . The test basically tried to assess respondent's view of how telecommunications eliminate trip pattern and physical movements in the city. The survey recorded 198 respondents (59\%) who reported that the use of telecommunications do not eliminate their physical movement while 137 (41\%) agreed that it eliminates physical movements. The results of the test reveal that calculated value is greater than the Table value at 1 degree of freedom and at $95 \%$ confidence interval. Therefore, it can be concluded that there is sufficient reason to believe that it does not eliminate physical movement in its entirety. This invariably portrays the complementary nature of the two interacting modes in their effort to overcome space.

This result is not surprising considering the teledensity of the country with 3.36 lines in 2003 and 7.77 lines in 2004 (Central Bank of Nigeria 2004). The level of development is thus not consistent with countries with considerably high tele-density. Arising from this is the need for face-to-face transaction in the city. In an economy where e-banking, e-shopping, teleconferencing is poor, interpersonal contact in a face-to-face manner is the only option. Furthermore, the purpose of the trip cannot be replaced by telecoms in this part of the coun-

Table 4. Distribution of trip types often substituted by respondents

\begin{tabular}{cccccccc}
\hline \multirow{2}{*}{ Trip Type } & \multicolumn{2}{c}{ Sabon Gari } & \multicolumn{2}{c}{ Samaru } & \multicolumn{2}{c}{ Total } \\
\cline { 2 - 7 } & $\mathrm{N}$ & $\%$ & $\mathrm{~N}$ & $\%$ & $\mathrm{~N}$ & $\%$ \\
\hline Work trip & 01 & 0.8 & 02 & 1.5 & 03 & 1.2 \\
\hline Social trips & 71 & 60.7 & 73 & 52.1 & 144 & 56.0 \\
\hline Shopping trips & 02 & 1.7 & 01 & 0.7 & 03 & 1.2 \\
\hline Business trips & 38 & 32.5 & 58 & 41.4 & 96 & 37.3 \\
\hline Recreational trips & 05 & 4.3 & 06 & 4.3 & 11 & 4.3 \\
\hline Total & 117 & 100 & 140 & 100 & 257 & 100 \\
\hline
\end{tabular}

Table 5. Distribution of respondent's trip types complemented by telecommunication usage

\begin{tabular}{ccccccc}
\hline \multirow{2}{*}{ Trip Type } & \multicolumn{2}{c}{ Sabon Gari } & \multicolumn{2}{c}{ Samaru } & \multicolumn{2}{c}{ Total } \\
\cline { 2 - 7 } & $\mathrm{N}$ & $\%$ & $\mathrm{~N}$ & $\%$ & $\mathrm{~N}$ & $\%$ \\
\hline Work trips & 24 & 14.7 & 48 & 27.9 & 72 & 21.5 \\
\hline Social trips & 65 & 39.9 & 72 & 41.9 & 137 & 40.9 \\
\hline Shopping trips & 27 & 16.6 & 10 & 5.8 & 37 & 11.0 \\
\hline Business trips & 43 & 26.4 & 41 & 23.8 & 84 & 25.1 \\
\hline Recreational trips & 04 & 2.4 & 01 & 0.6 & 05 & 1.5 \\
\hline Total & 163 & 100 & 172 & 100 & 335 & 100 \\
\hline
\end{tabular}

Table 6. Chi-Square test for level of significance

\begin{tabular}{cccccc}
\hline Variable & Calculated X $^{2}$ & Tabulated X & Df & CI & Remark \\
\hline Do telecommunications eliminate physical movements of respondents? & 11.10 & 3.84 & 1 & $95 \%$ & Sig. \\
\hline
\end{tabular}


try. Trip types like shopping, health, education and social trips are all carried out based on physical movements since the level of ICT is still low.

\section{Conclusions}

Transportation planners and policy makers have very well noted the impact that telecommunications have on transportation system. Remarkably, ICT usage works better than travel in some intra-urban trip types though vital trip patterns like trip to work and shopping have not been significantly altered in the study area. However, trips that are often time-consuming, expensive and dangerous can be better substituted using telecommunications and at the same time the function of the trip can still be achieved.

The use and patronage of telecommunications within urban Zaria has an increasingly important, far reaching influence upon intra-urban trips. Perhaps, it shapes the direction and pace of the economy of the town including its land use pattern and mobility demands. Telecommunications alone cannot satisfy the basic thrust of interaction, as most of it requires physical movement in the city. An integration of transportation and telecommunications will further ensure least-cost travel pattern as some unwarranted trips can be avoided. This integrated least-cost planning concerns public resource acquisition strategy that evaluates a wide range of telecommunications and transportation supply and demand options. This is, with a view to improving movement performance, to ensure reliability, availability and reduce to the barest minimum transport cost and environmental externality.

\section{References}

Abler, R.; Adams, J. and Gould, P. 1972. Spatial organization: the geographers' view of the world. Prentice Hall International Inc. London, 236.

Ayeni, B. 1975. Some determinants of the propensity to interact in an urban system. A case study of Jos, Nigeria, Nigerian Geographical Journal 18(2): 111-119.

Central Bank of Nigeria (CBN). 2004. Annual report and statement of account.

De Souza, R. 2005. Household transportation use and urban air pollution: a comparative analysis of Thailand, Mexico, and the United States. Published by Population Reference Bureau, June 2005.

Gbadamosi, K. T. 2004. Telecommuting and urban movement behaviour, in Vandu-Chikolo et al. (ed). Perspective on Urban Transportation in Nigeria. Published by NITT, Zaria.

Hanson, S. 2000. Off the road? Reflections on transportation geography in the information age, Journal of Transport Geography 6(4): 241-249.

Hoyle, B. and Smith, J. 1998. Transport and development: conceptual framework, in Hoyle. B. and Knowles, R. (eds.). Modern Transport Geography. $2^{\text {nd }}$ edition, John Wiley and Sons, New York, 27.

Lloyd, P. E. and Dicken, P. 1972. Location in space: theoretical approach to economic geography. $2^{\text {nd }}$ edition. Harper and Row Ltd., London. 54-72.

Moktanan, P. L. 1991. Telecommunication and travels state of the practice, state of the air transportation. Belhaven Press, London.
Niles, J. S. 1994. Beyond telecommuting: A new paradigm for the effect of telecommunications on Travel. US Department of Commerce, Springfield VA 22161 (103).

Ogunsanya, A. A. 2005. Geography in the information and communication technology age, in Presidential Address at the $47^{\text {th }}$ Annual Conference of the Nigerian Geographical Association held at the University of Port-Harcourt, Port-Harcourt, Nigeria, 14-17 August, 2005.

Ogunbodede, E. F. 2002. Telecommuting and travel pattern. A preliminary assessment of the state of the practice of the use of GSM in Lagos State, in A Paper Presented at the $45^{\text {th }}$ Annual Conference of the Nigerian Geographical Association held at the University of Ilorin, Ilorin $28^{\text {th }}$ May and $4^{\text {th }}$ June 2002.

Tolley, R. S. and Turton, B. J. 1995. Transport system policy and planning: A geographical approach. Longman Publishers, Singapore.

Ullman, E. L. 1956. The role of transportation and basis for interaction, in Thomas, W. L. (ed.) Man's role in Changing the Surface of the Earth. Chicago University Press, Chicago, U.S.A.

U. S. DOE. 1993. United States Department of Energy. Energy, emissions and social consequences of telecommuting: Technical report in 1993, Washington DC 20585.

V-Mobile News. 2004. Celebrating Lifestyle. Maiden edition ISSN 1116-3402, p. 35. 